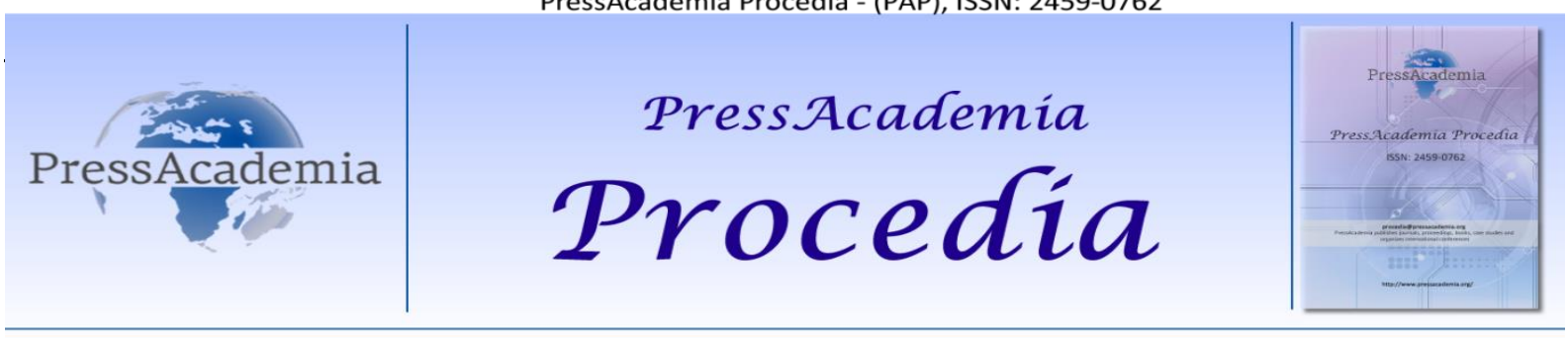

Global Business Research Congress (GBRC), May 24-25, 2017, Istanbul, Turkey.

\title{
A RESEARCH ON THE RELATION BETWEEN CULTURAL INTELLIGENCE LEVELS OF EXPATRIATES AND EXPATRIATE ADJUSTMENT
}

\author{
DOI: 10.17261/Pressacademia.2017.682 \\ PAP-GBRC- V.3-2017(109)-p.1019-1028
}

\section{Ece Kuzulu Kanaslan}

Sakarya University, Sakarya Üniversitesi SAÜSEM Binası, Sakarya, Turkey. ekuzulu@sakarya.edu.tr

To cite this document

Kuzulu, K. E. (2017). A research on the relation between cultural intelligence levels of expatriates and expatriate adjustment. PressAcademia Procedia (PAP), V.3, p.1019-1028.

Permemant link to this document: http://doi.org/10.17261/Pressacademia.2017.682

Copyright: Published by PressAcademia and limited licenced re-use rights only.

\begin{abstract}
Globalisation has been affecting people, countries and organisations and reshaping them. Expatriation process is significant in order to build close and effective relationships between MNEs headquarters and subsidiaries. Hence expatriate is one of the most important resources that MNEs need. Because of training, accommodation, transfer, schooling expenses, expatiates may be seen as the most expensive and even valuable employees of MNEs. Accordingly they may be named as the most costly employees of MNEs. This research was designed and conducted to examine the relation between cultural intelligence and expatiate adjustment. In order to analyse the hypotheses that are gathered from the literature, a scale with 31 items was used. The data was collected from 168 participants from different regions of the world via questionnaires. In the model of this research, cultural intelligence is an independent variable, expatriate adjustment is a dependent variable. The hypotheses were tested using regression analysis. The analysis of the results showed that cultural intelligence has positive effects on expatriate adjustment.
\end{abstract}

Keywords: Expatriate, cultural intelligence, expatriate adjustment, international human resources management, mnes.

JEL Codes: 160,120

\section{YABANCI YÖNETICILERDE KÜLTÜREL ZEKÂ iLE YABANCI YÖNETiCi UYUMU iLiŞKISi ÜZERINE BÍR ARAŞTIRMA}

\section{ÖZET}

Küreselleşme insanları, ülkeleri ve işletmeleri etkilemekte ve yeniden şekillendirmektedir. Uluslararası görevlendirme süreci çok uluslu şirketin genel merkezi ile bağlı kuruluşları arasında yakın ve etkili bir ilişki kurmak için son derece önemlidir. Bu sebeple yabancı yönetici, çok uluslu kuruluşun intiyaç duyduğu en önemli kaynaklardan biridir. Eğitim, barınma, taşınma, okul ücreti gibi harcamalar dolayısı ile yabancı yöneticiler çok uluslu kuruluşların en pahalı ve en değerli çalışanları olarak da değerlendirilebilir. Buna bağlı olarak, yabancı yöneticiler çok uluslu kuruluşların maliyeti en yüksek çalışanları olarak adlandırılabilirler. Araştırma kültürel zekâ ile yabancı yönetici uyumu arasındaki ilişkiyi incelemek üzere tasarlanmış ve yürütülmüştür. Literatür incelemesi sonucu ortaya konulan hipotezleri test etmek üzere 31 ifadeli bir ölçek kullanılmıştır. Veri toplama aracı olarak anketten yararlanılmış ve dünyanın çeşitli yerlerinden 168 yabancı yöneticiye ulaşılarak veriler toplanmıştır. Araştırmanın modelinde kültürel zekâ bağımsız değişken, yabancı yönetici uyumu bağımlı değişken görevi görmektedir. Araştırmanın hipotezleri çoklu ve basit doğrusal regresyon analizlerine tabi tutulmuştur. Analiz sonuçları kültürel zekânın yabancı yönetici uyumu üzerinde pozitif bir etkisi olduğunu göstermektedir.

Anahtar Kelimeler: Yabancı yöneticiler, kültürel zeka, yabancı yönetici uyumu, ululslararası insan kaynakları yönetimi, çok uluslu kuruluşlar JEL Kodları: 160, 120 


\section{GíRiş}

Uluslararası görevlendirmeler bir organizasyonun çalışanlarını kariyer gelişimi için yurtdışına göndermeyi, örgütsel bilgiyi yurtdışına transfer etmeyi, dünya çapında yeni pazarlara açılmayı ve uluslararası alt kuruluşu yönetmeyi gerektirir. Küresel iş dünyasında başarılı olmak için yabancı yöneticiler şirketler için gereklidir. Dolayısıyla, küreselleşme yabancı yöneticilerin ve uluslararası görevlendirmelerin sayısını artırmaktadır. Yabancı yöneticilerin başarılı adledilmelerindeki ilk ölçüt görevlendirme süresince ev sahibi ülkede kalmaları ve görevlerini tamamlamaları olarak belirtilmektedir. Yabancı yöneticilerin görevlerini tamamlamadan ayrılma sebepleri uluslararası insan kaynakları literatüründe önemli bir soru olarak karşımıza çıkmaktadır. Yabancı bir yönetici görevlendirmede başarılı olabilmek için hızı ve etkin bir şekilde kendisine yabancı olan bir ortama uyum sağlamalıdır, ancak bunu başaramayan yabancı yönetici sayısının oldukça fazla olduğu belirtilmektedir (Caligiuri v.d., 2001). Kültürlerarası uyum literatürüne göre yabancı yöneticiler yeni bir kültür ve bu kültürün gerçekleri ile karşılaştıklarında genellikle "kültür şoku" yaşamaktadırlar. Yabancı yöneticiler ve kültür konusu bir arada ele alındığında kültürel zekâ konusu göz ardı edilemez. Farklı kültürel ortamlarda, farklı kültürlerden kişiler ile birarada başarılı bir biçimde etkileşimde olmayı ve kültürel farklılıkların bilincinde olup onlara uygun olarak davranmayı ve farklı bir kültüre uyum sağlama becerisini ifade eden kültürel zekâ yabancı yönetici etkinliği konusuda önem teşkil etmektedir.

\section{LITERATURE INCELEMES}

\subsection{Yabancı Yöneticiler}

Küreselleşme araştırmaları 1980 ve 90'larda yöneticilerin firmalar arasında ve uluslararası anlamda hareketli bir biçimde çalışmalarının artması ile ivme kazanmıştır. Piyasalar kültürel bakımdan farklılaşmakta, bununla birlikte çalışanlar da yurtdışı görevlendirmeleri ile daha fazla karşı karşıya gelmektedir. Ulusların kültürleri arasındaki farklar örgütlerin ve çalışanlarının iletişim kurma, pazarlık etme, organize etme ve liderlik etme stillerini etkilemektedir (Hofstede, 1980; Offerman ve Hellman, 1997). Bunlara ek olarak kültür motivasyon, iş tatmini, örgütsel süreçler ve çıktılarında etkili olmaktadır.

\subsubsection{Yabancı Yönetici (Expatriate)}

Yabancı yönetici kavramı literatürde farklı biçimlerde tanımlanmaktadır. Uluslararası literatürde expatriate olarak bilinen yabancı yönetici, kendi ülkesine dönme amacı taşıyan ve yurtdışında yaşayan kişi olarak tanımlanmaktadır (Gullick, 1990). Yabancı yöneticiler, çalışıkları firma ya da devlet tarafından başka bir ülkedeki işletme birimine, geçici bir süreliğine bir işi tamamlamak ya da örgütün bir hedefine ulaşmasını sağlamak amacı ile gönderilmiş çalışanlar şeklinde de tanımlanabilir (Aycan \& Kanungo, 1997). Çok uluslu şirketler için yabancı yöneticiler bilgi transferi, bağlı kuruluşların ve bağımsız birimlerin kontrolü ve entegrasyonu gibi önemli konularda hizmet vermektedirler. Yabancı yöneticilere yurt dışı görevini kabul etmelerini sağlamak için örgüt tarafından barınma, çocuk bakımı, eşler için iş bulma ya da önerme gibi teşvikler sunulmaktadır.

Üçüncü ülke vatandaşları ve ana ülke vatandaşları yabancı yöneticiler olarak adlandırılmaktadırlar. Ana ülkede çalışmak üzere görevlendirilen ev sahibi ülke vatandaşları da bu kapsamda yer alabilir (Tüzüner, 2013). Expatriate, diğer bir deyişle yabancı yönetici kavramına olan ilgi giderek artmaktadır. Yabancı yönetici temini, eğitimi, performansı, görevlendirme, uyum ve yabancı yönetici başarısızlığı gibi konular örgütler için önemlidir çünkü bu yöneticilerin planlanan sonuçları elde edememelerinin maliyeti örgütler bakımından son derece yüksektir. Kültürel zekâ da yabancı yönetici performansı ve uyumu ile ilgili konular arasındadır. Literatürde yabancı yönetici uyumu ile kültürel zekâyı ilişkilendiren pek çok çalışmaya rastlanmaktadır.

\subsubsection{Yabancı Yöneticilerin Yurt Dışı Görevlendirmelerinde Karşılaştıkları Sorunlar}

Yabancı yöneticilerin yurt dışı görevlendirmelerinde karşılaştıkları sorunlar uyum sorunu, kültür şoku, yabancı dil sorunları ve aile sorunları olarak sıralanabilir. Bu çalışmada uyum sorunu ve kültür şoku üzerinde durulacaktır.

\subsubsection{Uyum Sorunu}

Yeni bir kültüre uyum sağlamanın zorluğu uluslararası görevlendirmelerde yabancı yöneticinin etkinliğini etkileyen faktörlerden biridir. Rothman'a (2006) göre yabancı yönetici, uluslararası görevlendirme süresince kültürel farklılıklara uyum sağlama, risk ile baş edebilme ve yeni deneyimlere yön verebilme doğrultusunda güçlü farkındalığa ve toleransa sahip olmalıdır. Mansor ve meslektaşları (2014), uluslararası görevi kabul etmeden önce yabancı yöneticilerin ev sahibi ülke ve kültürü hakkında araştırma yapması; yeni ülkenin, işin ve zamanlamanın kendisi için uygun olduğuna emin olması gerektiğini öne sürmektedir. Barker 2004 yılında yaptığı araştırmasında, Asya ülkelerinde görevlendirilen batılı proje müdürlerinin kültürel farklılıklar gibi çeşitli zorluklar ile karşı karşıya geldiği sonucuna ulaşmıştır. Adler'e (2008) göre yabancı yönetici görevlendirildiği yabancı ülkede zaman içinde geçirdiği balayı, kültür şoku, uyum ve üstatlık aşamalarını deneyimlemektedir. 


\subsubsection{Kültür Şoku}

1994'te Solomon kültür şokunu, farklı kültürler arasında sosyal olarak etkileşime geçme ve yeni kültürü tamamen farklı şekilde algılama sonucu oluşan; karışıklık, belirsizlik, değer çatışmaları ve gizli anlaşmazlıklara karşı oluşan psikolojik ve duygusal tepki, denge yoksunluğu olarak tanımlamıştır. Diğer bir kültür şoku tanımı da farklı bir kültürü ve hatta dili olan yabancı bir ülkeye gidildiğinde yabancı yöneticinin hissettiği duygu dalgalanmaları şeklindedir (Sims \& Schraeder, 2004). Araştırmacılara göre, farklı ülkeler farklı davranış biçimleri gerektiren çeşitli kurallar ve geleneklere sahip olduğundan; yabancı yöneticiler davranışlarını değiştirmeyi öğrenmelidirler (Anderson, 1994; Black \& Mendenhall, 1990). Kişi yeni bir ortamda yaşamaya başladığında, o ortama uygun davranışlar sergilemeyi bilmiyor ise kültür şoku semptomlarını hissetmeye başlayabilmektedir.

\subsection{Kültürel Zekâ}

Artan sayıda organizasyonun küreselleşmesi ve iş yerindeki demografik çeşitliliğin artması ile pek çok işletme çalışanlarının yüksek kültürel farkındalığa sahip olmasını istemektedir. Bu, farklı kültürel ve etnik kökene sahip kişiler ile çalışabilmeyi ve etkileşim kurabilmeyi içermektedir (Ang et.al., 2008). Bazı bireylerin kültürel çeşitlilik ile diğerlerine göre neden daha iyi başa çıkabildiği konusu giderek önem kazanmaktadır. Triandis'e (2006) göre bireyleri yargılayıcı olmaktan uzaklaştırmak, kültürel zekânın önemli bir yönünü teşkil etmektedir. Kişilikten farklı olarak, kültürel zekâ, zaman içerisinde gelişebilen bir yetenektir ve kültürler arası başarılı deneyimler ile ilişkilidir.

Kültürel zekâ, genel zekâ (IQ) ve duygusal zekâdan (EQ) farklıdır (Alon \& Higggins, 2005) Genel zekâ, rasyonel ve mantığa dayalı sözel ve sayısal zekâya karşııık gelmektedir. Duygusal zekâ (EQ), bireyin insan duygularını anlama ve iletme becerisini yansıtmaktadır. Kültürel zekâ konusundaki çalışmaların odak noktası mantık ya da duygulardan çok kültürlerarası etkileşimler ve davranışlardır. Kavramsal olarak kültürel zekâ "kültürlerarası yeterlilik" olarak ele alınabilir (Johnson, Lenartowicz \& Apud, 2006).

Ang ve Van Dyne'a (2008) göre kültürel zekâ dört bileşenden oluşan bir beceri setini yansıtmaktadır. Bu beceriler:

\subsection{1. Üst Bilişsel Kültürel Zekâ}

Üst bilişsel kültürel zekâ; kültürlerarası etkileşimlerin gerektirdiği farkındalık kapasitesine karşılık gelmektedir. Üst bilişsel kültürel zekâsı güçlü bireyler kendi kültürel varsayımlarını sorgulamakta, etkileşim sırasında yansıtmakta ve farklı kültürlerden kişiler ile etkileşimde bulunurken bu kişilerin kültürel bilgilerine uymaktadırlar. Örneğin üst bilişsel zekâsı yüksek bir Avrupalı yönetici Asyalı meslektaşları ile görüşmelerinde fikirlerini belirtirken bilinçli, ihtiyatlı ve duyarlı hareket etmektedir. Üst bilişsel zekâsı yüksek yöneticiler, etkileşimler öncesinde ve sırasında farklı toplumların kültürel tercihlerinin ve normlarının farkında olarak davranmaktadırlar. Kültürel zekânın bu bileşeni bilgi ve biliş kontrolü ile ilgilidir.

\subsubsection{Bilişsel Kültürel Zekâ}

Bilişsel kültürel zekâ, bir bireyin kültürel çevre ve kültür hakkındaki bilgi seviyesine karşılık gelmektedir. Bilişsel kültürel zekâ, genel kültürel olgular hakkındaki bilgileri olduğu kadar kültürel farklılıklar hakkındaki bilgileri de içermektedir. Bilişsel kültürel zekâ, kültürel zekânın önemli bir bileşenidir çünkü kültür hakkındaki bilgi insanların düşünce ve davranışlarını etkilemektedir. Bilişsel kültürel zekâsı yüksek bireyler, kültürel olarak farklı toplumlardan kişiler ile daha iyi etkileşimde bulunmaktadırlar. Kültürel bilgi diğer kültürlerdeki ekonomik, yasal ve sosyal sistemlerin bilgilerini de içermektedir (Ang et.al., 2008).

\subsubsection{Motivasyonel / Güdüleyici Kültürel Zekâ}

Motivasyonel / güdüleyici kültürel zekâsı yüksek olan bireyler, kültürler arası olaylara dikkat etmeye ve enerji harcamaya karşı doğal bir ilgi beslemektedirler (Deci ve Ryan, 1985) ve bu konuda kendilerine güvenmektedirler (Bandura, 2002). Örneğin, Japoncayı iyi bilen ve farkıı kültürlerden kişilerle etkileşimde olmayı seven bir Çinli yönetici, Japon bir meslektaşı ile karşılıklı konuşma başlatmaktan çekinmeyecektir. Bunun aksine Japoncayı yeni öğrenmekte olan bir Çinli yönetici, kültürler arası etkileşimde bulunmaya daha isteksiz olacaktır.

\subsubsection{Davranışsal Kültürel Zekâ}

Davranışsal kültürel zekâ, faklı kültürlerden kişilerle etkileşim halinde iken uygun sözlü ve sözlü olmayan yöntemleri kullanabilme becerisidir. Davranışsal kültürel zekâsı yüksek olan bireyler her kültürel etkileşimde davranışlarını uyumlu hale getirebilirler.

\subsection{Yabancı Yönetici Uyumu}

1998 yılında Black'in literatüre katkısından bu yana uyumun çok boyutlu doğası pek çok çalışmada kabul görmüş ve referans gösterilmiştir (Shaffer v.d., 1999). Yabancı yönetici uyumu kendi içinde iş uyumu, etkileşim uyumu ve genel uyum olmak 
üzere üçe ayrılmaktadır. İ̧̧ uyumu iş çevresine uyum sağlamak, etkileşim uyumu ev sahibi ülke vatandaşları ile kültürler arası ilişkilere uyum ve genel uyum da ev sahibi ülkeye uyum sağlamak anlamına gelmektedir.

Yabancı yönetici uyumu kültürler arası uyum ya da uluslararası uyum olarak da adlandırılmakta ve yeni bir kültürün değerlerine ve uygun davranış kalıplarına alışmada rahatlığı simgelemektedir (Black ve Mendenhall, 1990). Black ve meslektaşları (1991) yabancı yönetici uyumunun işle ilgili faktörler (rol açıklı̆ı/netliği, rol yeniliği), örgütsel faktörler (seçme, sosyalleşme, sosyal destek) ve iş dışı faktörler (kültürel yenilik, aile/eş uyumu) tarafından belirlendiğini iddia etmektedir. Yüksek dışa dönüklük, uyumluluk, sorumluluk, duygusal istikrar ve açıklık gibi kişilik özellikleri de yabancı yönetici uyumunu etkilemektedir (Caligiuri, 2006). Yabancı yönetici uyumunun zaman içinde gelişen bir süreç olduğu literatürde kabul gören bir görüştür (Bhaskar-Shinivas v.d., 2005).

Haslberger ve meslektaşlarına (2014) göre bireylerin uyum bileşenleri; algısal, duygusal ve davranışsal olmak üzere üçe ayrılmaktadır. Algısal uyum bileşeni, yabancı yöneticinin yeni çevre hakkındaki bilgi ve anlayışını içermektedir. Yabancı yönetici ev sahibi ülkedeki insanları doğru bir şekilde selamlamayı biliyor mu? Yabancı yönetici, ev sahibi ülkede cinsiyetler arasındaki genel ilişkilerin nasıl olduğunu biliyor mu? Yabancı yönetici, ev sahibi ülkede iş görüşmelerinin nasıl yürütüldüğünü biliyor mu? Etkili uyum yabancı yöneticinin duygularını içermektedir. Yabancı yönetici yeni bir çevrede olmaktan mutlu mu? Yabancı yönetici işlerin iyi gittiğini düşünüyor mu? Yabancı yönetici yeni bir dil öğrenmek için istekli mi ya da bundan korkuyor mu? Son olarak, davranışsal uyum bileşeni yabancı yöneticilerin fiziksel aktivitesini içerir. Yabancı yönetici, etkili davranışlar sergiliyor mu? Ev sahibi ülke vatandaşları, yabancı yöneticinin uyum sağladığını düşünüyor mu? Yabancı yönetici, ev sahibi ülke vatandaşlarını selamlamayı bilse bile uygulayabiliyor mu?

Yabancı yönetici uyumunu olumsuz yönde etkileyen çeşitli faktörler bulunmaktadır. Bu faktörlerden ikisi rol çatışması, yabancı yöneticinin rolünün yeni ve önceki rollerden farklı olması ve karşılanmayan rol beklentileri olarak sayılabilir (Aryee \& Stone, 1996). Ev sahibi ülke vatandaşlarının desteği yalnızca yabancı yönetici uyumunu kolaylaştırmakla kalmaz, aynı zamanda yabancı yönetici uyumunu negatif yönde etkileyen faktörleri de azaltır. Örneğin Aryee ve Stone (1996), rol çatışmasının yabancı yöneticinin iş uyumu ile negatif ilişkide olduğunu iddia etmektedir. Bu gibi durumlarda ev sahibi ülke vatandaşlarından gelen bilgi desteği rol çatışmasının yabancı yönetici uyumu üzerinde yarattığı olumsuz etkiyi önemli ölçüde azaltmaktadır (Caliguiri \& Lazarova, 2002).

Uyum bileşenleri ile uyum sürecinin arasındaki ilişkinin hiçbir zaman tamamen öngörülemeyeceği iddia edilmektedir. Burada söz konusu süreç çok karmaşıktır. Ancak, yabancı yöneticinin deneyimi, geçmişi ve uyum aşamalarının bilinmesi ile uyum süreci aşağı yukarı tahmin edilebilir.

\section{VERI VE YÖNTEM}

\subsection{Araştırmanın Modeli}

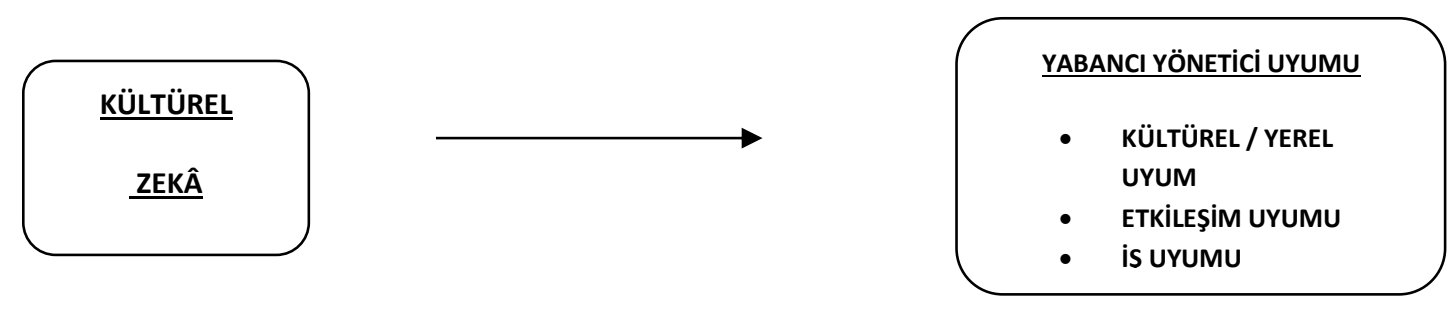

\subsection{Araştırmanın hipotezleri}

H1: Yabancı yöneticilerin kültürel zekâ seviyesi yabancı yöneticilerin uyumunu etkiler.

H2: Kültürel zekâ cinsiyete göre farklılık göstermektedir.

H3: Uyum cinsiyete göre farklılık göstermektedir.

H4: Kültürel zekâ yaşa göre farklılık göstermektedir.

H5: Uyum yaşa göre farklılık göstermektedir.

\subsubsection{Araştırmanın Evreni ve Örneklemi}

Bu çalışmada ortaya koyulan hipotezleri test etme amacı ile ampirik bir araştırma yapılmıştır. Çok uluslu şirketlerde çalışmakta olan 168 sayıda yabancı yöneticiye kolayda örnekleme yolu ile ulaşılmış ve veriler toplanmıştır. 


\subsubsection{Veri Toplama Teknikleri}

Araştırmamızda veriler anket yöntemi ile toplanmıştır. Anket çalışmasına katılan yabancı yöneticilere e-mail ve sosyal medya (linkedin, expatfinder, internations) üzerinden ulaşıımıştır. Araştırmada katılımcılara yurt dışı görevlendirmeleri, kendileri ve işleri hakkındaki algıları, tutumları içeren soruların yanı sıra cinsiyetleri, yaşları, önceki deneyimleri de sorulmuştur.

\subsubsection{Yararlanılan Ölçekler}

\subsubsection{Kültürel Zekâ Ölçeği}

Kültürel Zekâ Ölçeği Ang ve meslektaşları tarafından 2004 yılında oluşturulmuştur. Ang ve meslektaşları (2004) ölçeği ilk olarak her bileşeni 13-14 ifade ile ölçecek şekilde toplamda 53 maddeden oluşacak biçimde tasarlamışlardır. Daha sonra ifade sayısı 40'a düşürülmüş ve en sonunda 20 ifade ile ölçeğin en son haline ulaşılmıştır. Çapraz geçerlilik analizleri, Kültürel Zekâ Ölçeğinin örneklem, zaman ve ülkeler (Singapur ve $A B D$ ) üzerinden geçerlilik ve güvenilirliğine güçlü bir biçimde desteklemektedir. Ayrıca, sonuçlar kültürel zeka boyutları ve kültürler arası spesifik çıktılar arasında sistematik bir ilişkiler modeli olduğuna işaret etmektedir (Ang v.d., 2004). Kültürel zekâ ölçeği Likert tipi bir ölçektir.

\subsubsection{Yabancı Yönetici Uyumu Ölçeği}

Çalışmamızda yabancı yönetici uyumu Black ve Stephen'ın 1989 yılıda geliştirdikleri Yabancı Yönetici Uyum Ölçeği kullanılarak ölçülmüştür. Black ve Stephen'ın Yabancı Yönetici Uyum Ölçeği Likert tipi bir ölçektir ve katılımcılar 1 kesinlikle katılmıyorum ile 7 tamamen katılıyorum ifadeleri arasında kendilerine en uygun puanı seçmektedirler. Yabancı Yönetici Uyum Ölçeği iş, genel çevre ve ev sahibi vatandaşlar ile etkileşim hakkında 11 ifade içermektedir. Yabancı yöneticinin iş uyumunu ölçmek üzerine olan ifadeler yabancı yöneticinin iş ile ilgili sorumlulukları ve yerli meslektaşlar ile birlikte çalışabilme hakkında 2 sorudan oluşmaktadır. Etkileşim uyumu ev sahibi ülke vatandaşları ile genel olarak etkileşim, örgüt dışındaki ev sahibi ülke vatandaşları ile birlikte çalışabilme ve yerli astları yönetmek üzerine 3 ifade ile ölçülmektedir. Yabancı yöneticilerin genel uyumunu ölçen ifadeler, ev sahibi ülkedeki ulaşım sistemi ve genel yaşam koşullarını içeren 6 ifadeden oluşmaktadır.

\section{BULGULAR VE TARTIŞMA}

\subsection{Demografik Bulgular}

Araştırmaya araştırma kapsamına giren 168 yabancı yönetici katılmıştır. Yabancı yöneticilerin 70'i kadın 98'i erkektir. Diğer bir deyişle katılımcıların \%41,7'si kadın, \%58,3'ü ise erkektir. Anketleri cevaplayan yabancı yöneticilerin \%35,1'i 31-40 yaş arasında, \%30,4'ü 21-30 yaş arasında, \%18,5'i 41-50 yaş arasında, \%8,9'u 51-60 yaş arasında ve \%7,1'i 61 yaş ve üzeridir. Dolayısı ile katılımcıların çoğunluğu 31 ile 41 yaş arasındadır.

Tablo 1: Katılımcıların Demografik Özellikleri

\begin{tabular}{lcccccc}
\hline Değişken & N & Frekans & \% & Ortalama & Min & Max \\
\hline Cinsiyet & 168 & & & & & - \\
\hline Kadın & & 70 & 41,7 & - & - & - \\
Erkek & & 98 & 58,3 & - & $\mathbf{3 8 , 4 4}$ & $\mathbf{2 1}$ \\
\hline Yaş & 168 & - & - & - & - \\
\hline $\mathbf{2 1 - 3 0}$ yaş arası & & 51 & 30,4 & - & - & - \\
$\mathbf{3 1 - 4 0}$ yaş arası & & 59 & 35,1 & - & - & - \\
$\mathbf{4 1 - 5 0}$ yaş arası & & 31 & 18,5 & - & - & - \\
$\mathbf{5 1 - 6 0}$ yaş arası & & 15 & 8,9 & 7,1 & - & - \\
$\mathbf{6 1}$ yaş ve üzeri & & 12 & & - & - & - \\
\hline
\end{tabular}

Araştırmaya araştırma kapsamına giren 168 yabancı yönetici katılmıştır. Yabancı yöneticilerin 70'i kadın 98'i erkektir. Diğer bir deyişle katılımcıların \%41,7'si kadın, \%58,3'ü ise erkektir. Anketleri cevaplayan yabancı yöneticilerin \%35,1'i 31-40 yaş arasında, \%30,4'ü 21-30 yaş arasında, \%18,5'i 41-50 yaş arasında, \%8,9'u 51-60 yaş arasında ve \%7,1'i 61 yaş ve üzeridir. Dolayısı ile katılımcıların çoğunluğu 31 ile 41 yaş arasındadır. 
Tablo 2: Deneklerin Kültürel Zekâ Düzeyleri

\begin{tabular}{clcl}
\hline & $N$ & Ortalama & St. Sapma \\
\hline Kültürel Zekôa & 168 & 5,3089 &, 80551 \\
Üst-bilişsel Kültürel Zekô & 168 & 5,7173 &, 93524 \\
Bilişsel Kültürel Zekô & 168 & 4,8105 & 1,10794 \\
Motivasyonel Kültürel Zekôa & 168 & 5,6875 &, 91509 \\
Davranışsal Kültürel Zekôa & 168 & 5,0804 & 1,22331 \\
\hline
\end{tabular}

Tablo 2'de araştırmaya katılan yabancı yöneticilerin kültürel zekâ ortalamasının 5,3 olduğu, üst bilişsel kültürel zekâ ortalamasının 5,7 ile en yüksek ve bilişsel kültürel zekâ ortalamasının 4,8 ile en düşük düzeyde yer aldığı görülmektedir.

Tablo 3: Deneklerin Yabancı Yönetici Etkinliği Düzeyleri

\begin{tabular}{ccccc}
\hline & $N$ & Ortalama & St. Sapma \\
\hline Yabana Yönetici Uyumu & 168 & 5,5341 &, 91842 & \\
\hline
\end{tabular}

Tablo 3'e bakıldığında ankete katılan yabancı yöneticilerin etkinlik düzeylerinin ortalamasının 5,3 olduğu görülmektedir. Ayrıca, yabancı yönetici performansı 5,8 ortalama ile en yüksek; geri çekilme niyeti ise 3,1 ortalama ile en düşük düzeyde yer almaktadır.

\subsection{Faktör Analizi}

Literatürde KMO istatistiğinin 0,80'den büyük olması tavsiye edilmekte ise de 0,60 ve fazla olan değerler de kabul edilmektedir (Yong \& Pearce, 2013). Bartlett testi araştırmadaki değişkenler arasındaki ilişkinin yeterli olmasına ilişkin bir göstergedir ve anlamlılık değerinin 0,05'ten küçük olması istenmektedir (Yong \& Pearce, 2013).

Kültürel Zekâ ölçeğine ait 20 ifade açıklayıcı faktör analizine tabi tutulmuştur. Kültürel Zekâ ölçeğinin KMO istatistiği 0,873 'tür $(>0,60)$ ve örneklem büyüklüğünün faktör analizine tabi tutmada yeterli olduğunu göstermektedir. Barlett testi Chi katsayısı ise anlamlıdır $(p=0,000<0,05)$. Yabancı yönetici etkinliği ölçeğinin KMO istatistiği 0,852 'dir $(>0,60)$ ve örneklem büyüklüğünün faktör analizine tabi tutmada yeterli olduğunu işaret etmektedir. Barlett testi Chi katsayısı ise anlamlıdır $(p=0,000<0,05)$.

\subsection{Güvenilirlik Analizi}

Güvenilirlik analizi sonucunda 20 ifadeli Kültürel Zekâ ölçeğine ait Crombach's Alpha değeri 0,909 olarak ve 8 ifadeli Yabancı Yönetici Uyumu ölçeğine ait Crombach's Alpha değeri 0,877 olarak hesaplanmıştır.

\subsection{Korelasyon Analizi}

Kültürel zekâ ile yabancı yönetici uyumu arasındaki ilişkinin kuvvetinin ve yönünün belirlenmesi amacı ile uygulanan korelasyon analizi sonuçlarına göre; iki değişken arasında doğrusal ve pozitif yönlü bir ilişki bulunmaktadır $(r=0,628)$. Buna ek olarak iki değişken arasındaki ilişkinin 0,01 düzeyinde istatistiksel olarak anlamlı olduğu sonucuna ulaşılmıştır $(p<0.01)$.

\subsection{Kültürel Zekânın Yabancı Yönetici Uyumu Üzerindeki Etkisi}

Kültürel zekânın yabancı yönetici uyumu üzerindeki etkisinin incelenmesi için basit doğrusal regresyon analizi gerçekleştirilmiştir. Tablo 4'te görüldüğü üzere regresyon analizi sonuçlarına göre, yabancı yönetici uyumundaki değişkenliğin \%39'unu açıklayan $\left(R^{2}=0,395\right)$ modelde, kültürel zekânın yabancı yönetici uyumu üzerinde pozitif yönde anlamlı bir etkiye sahip olduğu saptanmıştır $(\beta=0,628 ; p=0,000<0,05)$.

Tablo 4: Kültürel Zekânın Yabancı Yönetici Uyumu Üzerindeki Etkisine ilişkin Regresyon Analizi Sonuçları

\begin{tabular}{|c|c|c|c|c|}
\hline \multirow[b]{2}{*}{ Bağımsız Değişken } & \multicolumn{4}{|c|}{$\begin{array}{l}\text { Bağımlı değişken } \\
\text { Yabancı Yönetici Uyumu }\end{array}$} \\
\hline & Sabit & Beta & $\mathrm{t}$ & $\mathrm{p}$ \\
\hline & 1,731 & & 4,683 & ,000 \\
\hline Kültürel Zekâ & & 628 & 10,404 & ,000 \\
\hline$R^{2}$ & ,395 & & & \\
\hline
\end{tabular}




\begin{tabular}{ll}
\hline Düzeltilmis $R^{2}$ &, 391 \\
$F$ & 108,243 \\
$P$ &, 000 \\
Durbin-Watson & 2,013
\end{tabular}

Bu sonuca göre kültürel zekâda meydana gelen 1 birimlik artış yabancı yönetici uyumunda 0,628 birimlik bir artışa neden olmaktadır. Kültürel zekânın yabancı yönetici uyumundaki değişkenliğin \%39'unu açıklaması, yabancı yönetici uyumunu açıklayan başka faktörlerin de varlığına işaret etmektedir. Yabancı yönetici uyumunu etkileyen kültürel zekâ dışındaki faktörler arasında, yabancı yöneticinin eşinin ev sahibi ülkeye uyumu, çocukların okul ve sosyal çevreye uyum sağlama dereceleri, ev sahibi ülke vatandaşı çalışanların yabancı yöneticiye karşı tutumları gibi etkenler sayılabilir.

Regresyon Denklemi:

Y: Yabancı yönetici uyumu X1: Kültürel zekâ

$\mathrm{Y}=1,731+0,628 \times 1$

"Yabancı yöneticilerin kültürel zekâ seviyesi yabancı yöneticilerin uyumunu etkiler" hipotezi, kültürel zekânın yabancı yönetici uyumu üzerinde anlamlı etkiye sahip olması nedeniyle kabul edilmiştir.

\subsection{Araştırmadaki Değişkenlerin Cinsiyete Göre Farklılık Gösterip Göstermediğine İlişkin Bulgular}

Yabancı yönetici uyumunun, yabancı yönetici geri çekilme niyetinin ve yabancı yönetici kültürel zekâsının cinsiyete göre farklıık gösterip göstermediğini belirlemek amacı ile t-testi kullanılmıştır

Yapılan analizin tanımlayıcı istatistikleri Tablo 5'te gösterilmektedir.

Tablo 5: Araştırmadaki Değişkenlerin Cinsiyete Göre Farklılık Gösterip Göstermediğine ilişkin Ortalamalar

\begin{tabular}{lcccc}
\hline & Cinsiyet & N & Ortalama & Std. S. \\
\hline Yabancı Yönetici Uyumu & Kadın & 70 & 5,4065 & 1,09285 \\
Kültürel Zekâ & Erkek & 98 & 5,6252 &, 76320 \\
& Kadın & 70 & 5,2721 &, 93888 \\
& Erkek & 98 & 5,3352 &, 69883 \\
\hline
\end{tabular}

T-Testi sonuçlarına göre değişkenlerin hem genel olarak hem de boyutları bakımından anlamlılı değerlerinin 0,05 değerinden yüksek olduğu tespit edilmiştir. Dolayısıyla araştırmada yer alan değişkenler, kadın ya da erkek olmaya göre farklılık göstermemektedir.

Uygulanan $\mathrm{t}$ testine ilişkin sonuçlar aşağıdaki gibidir.

Tablo 6: Araştırmadaki Değişkenlerin Cinsiyete Göre Farklılık Gösterip Göstermediğine İlişkin t-Testi Sonuçları

\begin{tabular}{llcccc}
\hline & & \multicolumn{3}{c}{ Levene Testi } & \multicolumn{2}{c}{ t testi } \\
\cline { 3 - 6 } & & $\mathrm{F}$ & $\mathrm{P}$ & $\mathrm{t}$ & $\mathrm{P}$ \\
\hline Yabancı Yönetici Uyumu & Eşit v. & 10,372 &, 002 & $-1,528$ &, 128 \\
& Eşit olm.v. & & & $-1,442$ &, 152 \\
Kültürel Zekâ & Eşit v. & 7,583 &, 007 &,- 499 &, 618 \\
& Eşit olm.v. & & &,- 476 &, 635 \\
\hline
\end{tabular}

\subsection{Araştırmadaki Değişkenlerin Yaşa Göre Farklılık Gösterip Göstermediğine İlişkin Bulgular}

Kültürel zekâ ve yabancı yönetici uyumu değişkenlerinin yaşlarına göre farklılık gösterip göstermediğini belirlemek için tek yönlü varyans analizinden (ANOVA) yararlanılmıştır. Yapılan analize yönelik homojenlik sonuçları aşağıda Tablo 7'de gösterilmektedir.

Tablo 7: Araştırmadaki Değişkenlerin Yaşa Göre Farklııık Gösterip Göstermediğine ilişkin Homojenlik Testi Sonuçları

\begin{tabular}{lcccc}
\hline & Levene İst. & df1 & df2 & $p$ \\
\hline Kültürel Zekâ & 1,678 & 34 & 121 & 0,22 \\
Uyum & 1,703 & 34 & 121 & 0,19 \\
\hline
\end{tabular}


Araştırmadaki değiş̧enlerin yaşa göre farklılık gösterip göstermediğine ilişkin homojenlik testi sonucunda elde edilen Levene İstatistiği değerlerine göre, elde edilen $p$ değerlerinin 0,05 'ten büyük olduğu ortaya çıkmıştır. Bu durumda grup varyanslarının eşit olduğu görülmüş ve ANOVA analizi için gerekli şart sağlanmıştır. Araştırmadaki değişkenlerin yaşa göre farklılık gösterip göstermediğine ilişkin tanımlayıcı istatistiklere ve ANOVA değerlerine ait sonuçlar Tablo 8'de gösterilmektedir.

Tablo 8: Araştırmadaki Değişkenlerin Yaşa Göre Farklılık Gösterip Göstermediğine ilişskin Tanımlayıcı İstatistikler ve ANOVA değerleri

\begin{tabular}{|c|c|c|c|c|c|c|}
\hline & \multicolumn{4}{|c|}{ Tanımlayıcı İst. } & \multicolumn{2}{|c|}{ ANOVA D. } \\
\hline & $21-30$ & 51 & 4,231 & 0,878 & & \\
\hline \multirow[t]{2}{*}{ Kültürel Zekâ } & $41-50$ & 31 & 4,065 & 0,971 & ,756 & ,856 \\
\hline & $51-60$ & 15 & 4,024 & 0,793 & & \\
\hline \multirow[t]{4}{*}{ Uyum } & $31-40$ & 59 & 3,655 & 0,652 & & \\
\hline & $41-50$ & 31 & 3,952 & 0,857 & ,866 & ,705 \\
\hline & $51-60$ & 15 & 3,479 & 0,698 & & \\
\hline & $60+$ & 12 & 3,968 & 0,793 & & \\
\hline
\end{tabular}

Tablo 8'de yer alan analiz sonuçlarına göre, kültürel zekâ ve yabancı yönetici uyumunun anlamlılık değerlerinin 0,05'ten yüksek olduğu görülmektedir. Dolayısıyla kültürel zekâ ve yabancı yönetici uyumu değişkenlerinin yaşlarına göre farklılık gösterip göstermediğini belirlemek için yapılan tek yönlü varyans analizi (ANOVA) sonuçlarına göre bu değişkenlerin yaşa göre anlamlı farklılık göstermediği ortaya çıkmıştır.

\section{SONUÇ}

"Yabancı yöneticilerin kültürel zekâ seviyesi yabancı yöneticilerin uyumunu etkiler." hipotezi basit doğrusal regresyon analizi ile test edilmiştir. Regresyon analizinden önce normal dağılıma uygunluk, otokorelasyon olmaması, doğrusallık ve varyansların homojenliği varsayımlarını geçerli olduğu saptanmıştır. Basit doğrusal regresyon analizi sonuçlarına göre yabancı yöneticilerin kültürel zekâ seviyeleri ile yabancı yönetici uyumu arasında pozitif yönlü ve istatistiksel olarak anlamlı bir ilişki bulunduğu görülmektedir. Analiz sonuçlarına göre hipotez kabul edilmiştir. Yabancı yöneticilerin kültürel zekâ seviyeleri arttıkça, yabancı yönetici uyumu da artmaktadır. Dolayısı ile kültürel zekâ seviyesi yüksek bir yabancı yönetici yurt dışında görevlendirildiğinde, görevlendirildiği ülkenin şartlarına kolaylıkla uyum sağlamaktadır.

"Kültürel zekâ cinsiyete göre farklılık göstermektedir" hipotezini test etmek üzere t-testi yapılmıştır. T-Testi sonuçlarına göre yabancı yöneticilerde kültürel zekâ, kadın ya da erkek olmaya göre farklııık göstermemektedir. Hipotez reddedilmiştir.

"Uyum cinsiyete göre farklılık göstermektedir" hipotezini test etmek üzere t-testi yapılmıştır. T-Testi sonuçlarına göre yabancı yönetici uyumu, cinsiyete göre farklılık göstermemektedir. Hipotez reddedilmiştir.

"Kültürel zekâ yaşa göre farklılık göstermektedir" hipotezini test etmek üzere t-testi ve ANOVA analizleri gerçekleştirilmiştir. Yapılan analiz sonuçlarına göre yabancı yöneticilerde kültürel zekânın yaşa göre farklılaşmadığı saptanmıştır ve Hipotez reddedilmiştir.

"Uyum yaşa göre farklılık göstermektedir" hipotezini test etmek üzere t-testi ve ANOVA analizleri gerçekleştirilmiştir. Yapılan analizlerde yabancı yöneticilerde uyumun yaşa göre farklılaşmadığı saptanmıştır ve Hipotez reddedilmiştir.

Gelecekte yapılacak olan araştırmalar kültürler arası eğitime ev sahibi ülke vatandaşlarını da dâhil etmeyi göz önünde bulundurabilir. Yine ileriki araştırmalarda, bulguların geçerliliğinin güçlendirilmesi için verilerin yabancı yönetici, yabancı yöneticinin amiri ve ev sahibi ülke vatandaşlarından toplanması önerilebilir. Ayrıca kadın ve erkek yabancı yöneticilerin ev sahibi ülkeye uyum sağlamaları konusundaki farklılıkların araştırılması önerilebilir.

Uluslararası görevlendirmelerde kadın çalışanların oranının düşük seviyede olması hususu (Caliguiri \& Tung, 1999) ayrı ve önemli bir çalışma konusudur ve bu durumun sebepleri üzerine uygulamalı araştırmalar yürütülmelidir.

Literatür taraması sonucunda, uluslararası insan kaynakları araştırmalarında yabancı yöneticilerin kendilerine önerilen deniz aşırı görevlendirmeleri ne oranda kabul ettikleri üzerinde çok az çalışıımış bir konu olarak karşımıza çıkmaktadır (Harvey \& Wiese, 1998). Bu bağlamda, ileriki çalışmalarda yabancı yöneticilerin kendilerine önerilen görevleri kabul etmelerinde önemli olan kriterlerin ve kabul etme oranlarını etkileyen faktörlerin araştırılması tavsiye edilebilir. Yabancı yöneticilerin geri 
çekilme niyeti üzerine yürütülecek gelecekteki araştırmalar, görevlendirme hakkında bireylerin ve örgütün görüşlerini ve değerlendirmelerini ve kültürler arası uyumun bu yapının neresinde yer aldığını göz önünde bulundurmalıdırlar.

\section{KAYNAKLAR}

Adler, N.J. (2008). International Dimension of Organizational Behaviour. USA: Thomson South Western.

Alon, I., Higgins, J. M. (2005). Global leadership success through emotional and cultural intelligences. Business Horizons, 48 (6): $501-512$.

Anderson, L. E. (1994). A new look at an old construct: Cross-cultural adaptation. International Journal o f Intercultural Relations, 18, 293328.

Ang, S., Van Dyne, L. \& Koh, C. (2008). Development and Validation of the CQS, in Ang and Van Dyne. Ed. Handbook of Cultural Intelligence: Theory, Measurements, and Applications, London: M.E.Sharpe.

Aryee, S. \& Stone, R. J. (1996). Work experiences, work adjustment and psychological well-being of expatriate employees in Hong Kong. The International Journal of Human Resource Management 7(1):150-164.

Aycan, Z., Kanungo, R.N. (1997). Current issues and future challenges in expatriate management. In Z. Aycan, Ed. Expatriate management: Theory and research. Greenwich, Connecticut: JAI Press. 245- 260.

Bandura, A. (2002). Social cognitive theory in cultural context. Applied Psychology: An International Review, 51, 269-290.

Barker, D.W. (2004). Organizational Commitment of Expatriate Manager in China. International Journal of Management \& Organisational Behaviour, 3(2): 504-520.

Bhaskar-Shrinivas, P., Shaffer, M.A., \& Harrıson, D.A. (2005). Input-based and Time-based Models of International Adjustment: Metaanalytic Evidence and Theoretical Extensions. Academy of Management Journal, 48, 257-281.

Black, J. S. (1998). Work Role Transitions: A Study Of American Expatriate Managers in Japan. Journal of International Business Studies, 19(2): 277-294.

Black, J. S., Mendenhall, M. (1990). Cross-cultural training effectiveness: a review and a theoretical framework for future research. Academy of Management Review, 15(1), 113-136.

Black, J. S., Mendenhall, M. (1991). The u-curve adjustment hypothesis revisited: A review and theoretical framework. Journal of International Business Studies, 22, 225-247.

Black, J. S., Stephens, G. K. (1989). The influence of the spouse on American expatriate adjustment and intent to stay in Pacific Rim overseas assignments. Journal of Management, 15, 529-544.

Caligiuri, P. (2006). Developing global leaders. Human Resource Management Review, 16, 219-228.

Caligiuri, P.M., \& Lazarova, M. (2002). A Model for the Influence of Social Interaction and Social Support on Female Expatriates CrossCultural Adjustment. Int. J. Of Human Resources Management, 13:5 August 2002 761-772.

Deci, E.L., Ryan, R.M. (1985). Intrinsic motivation and self-determination in human behavior. New York: Plenum.

Gullick, C. J. M. R. (1990). Expatriate British executives and culture shock. Studies in Third World Societies, 42: 173-206.

Harvey, M., Wiese, D. (1998). The Dual-career Couple: Female Expatriates and Male Trailing Spouses. Thunderbird International Business Review, 40, 4, 359-378.

Haslberger, A., Brewster, C., \& Hippler, T. (2014). Managing performance abroad: A new model for understanding expatriate adjustment. London: Routledge.

Hofstede, G. (1980). Culture's consequences: International differences in work related values. Beverly Hills: Sage Publications.

Johnson, J. P., Lenartowicz, T. \& Apud, S. (2006). Cross-Cultural Competence in International Business: Toward a Definition and a Model. Journal of International Business Studies, Vol. 37, No. 4 (Jul., 2006), pp. 525-543.

Mansor, M. F. B., Hamid, N. B. A., Kamil, S. B., \& Abu. N. H. (2014). Determinants of Expatriate Manager Failures in the International Assignment. Advances in Environmental Biology, 8(9), 584-592.

Offermann, L. R., Hellmann, P. S. (1997). Cultures consequences for leadership behavior: National values in action. Journal of Cross-Cultural Psychology, 28(3), 342-351.

Rothmann, M.V. (2006). Correlates of expatriates cross-cutural adjustment. Journal of Management Dynamic, 5(1): 543-566.

Sims, R. H., Schraeder, M. (2004). An examination of salient factors affecting expatriate culture shock. Journal of Business and Management, 70(1), 73-87. 
Shaffer, M. A., Harrison, D. A., \& Gilley, K. M. (1999). Dimensions, determinants, and differences in the expatriate adjustment process. Journal of International Business Studies, 30, 557-582.

Solomon, C. M. (1994). Success abroad depends on more than job skills. Personnel Journal, 4, 51-59.

Triandis, H.C. (2006). Cultural intelligence in organizations. Group and Organization Management, 31, 20-26.

Tüzüner, V.L. (2013). Uluslararası İnsan Kaynakları Yönetimi. Uyargil, C., Adal, Z.,Ataay, İ. D., Acar, A.C., Özçelik, O., Sadullah, Ö. \& Tüzüner, V.L. İnsan Kaynakları Yönetimi içinde, (3.Baskı), Beta Yayınları, İstanbul.

Yong, A.G., Pearce, S. (2013). A Beginner's Guide to Factor Analysis: Focusing on Exploratory Factor Analysis. Tutorials in Quantitative Methods for Psychology, 9(2), 79-94. 